NBER WORKING PAPER SERIES

\title{
SHOULD WE HAVE AUTOMATIC TRIGGERS FOR UNEMPLOYMENT BENEFIT DURATION AND HOW COSTLY WOULD THEY BE?
}

\author{
Gabriel Chodorow-Reich \\ Peter Ganong \\ Jonathan Gruber \\ Working Paper 29703 \\ http://www.nber.org/papers/w29703 \\ NATIONAL BUREAU OF ECONOMIC RESEARCH \\ 1050 Massachusetts Avenue \\ Cambridge, MA 02138 \\ January 2022
}

We thank Isabel Allum and Nicolas Wuthenow for excellent research assistance and Pauline Leung for discussing the paper. Ganong thanks the Becker Friedman Institute at the University of Chicago for generous funding. Chodorow-Reich thanks the Alfred P. Sloan Foundation and Harvard Ferrante Fund. The views expressed herein are those of the authors and do not necessarily reflect the views of the National Bureau of Economic Research.

NBER working papers are circulated for discussion and comment purposes. They have not been peer-reviewed or been subject to the review by the NBER Board of Directors that accompanies official NBER publications.

(C) 2022 by Gabriel Chodorow-Reich, Peter Ganong, and Jonathan Gruber. All rights reserved. Short sections of text, not to exceed two paragraphs, may be quoted without explicit permission provided that full credit, including $(\odot)$ notice, is given to the source. 
Should We Have Automatic Triggers for Unemployment Benefit Duration And How Costly

Would They Be?

Gabriel Chodorow-Reich, Peter Ganong, and Jonathan Gruber

NBER Working Paper No. 29703

January 2022

JEL No. E24,E32,E62,H53,J65

\title{
ABSTRACT
}

We model automatic trigger policies for unemployment insurance by simulating a weekly panel of individual labor market histories, grouped by state. We reach three conclusions: (i) policies designed to trigger immediately at the onset of a recession result in benefit extensions that occur in less sick labor markets than the historical average for benefit extensions; (ii) the ad hoc extensions in the 2001 and 2007-09 recessions in total cover a similar number of additional weeks as common proposals for automatic triggers, but concentrate coverage more in weaker labor markets; (iii) compared to ex post policy, the cost of common proposals for automatic triggers is close to zero.

\author{
Gabriel Chodorow-Reich \\ Department of Economics \\ Harvard University \\ 1805 Littauer Center \\ Cambridge, MA 02138 \\ and NBER \\ chodorowreich@fas.harvard.edu \\ Peter Ganong \\ Harris School of Public Policy \\ University of Chicago \\ 1307 East 60th Street \\ Chicago, IL 60637 \\ and NBER \\ ganong@uchicago.edu
}

Jonathan Gruber

Department of Economics, E52-434

MIT

77 Massachusetts Avenue

Cambridge, MA 02139

and NBER

gruberj@mit.edu 


\section{Introduction}

Unemployment Insurance (UI) is a significant part of the social insurance safety net in the U.S. and around the world. The experience of COVID-19 illustrates the critical role that UI can play in the face of enormous aggregate shocks. It also highlights an issue that has been a perennial focus of UI policy: how the duration of benefits should depend on the state of the economy.

UI benefits are currently set to 26 weeks in most states. Under current law, a state enters into extended benefits (EB) if its insured or total unemployment rate exceeds legislated thresholds, with additional duration of 13 or 20 weeks. The current EB system has two potential shortcomings. First, the stringency of the trigger thresholds (including allowing states to opt out of the less stringent triggers) means that the system rarely actually triggers. Second, the additional 13 or 20 weeks may provide inadequate coverage during severe recessions. In response, Congress has enacted temporary additional extensions during each recession over the past 40 years, with extensions on 5 separate occasions ranging from 6 to 53 weeks.

For decades, economists have recommended replacing a system where extended durations of UI benefits are decided by legislative fiat to a more systematic linkage between benefit durations and economic conditions (McKay and Reis, 2021; Chodorow-Reich and Coglianese, 2019; Mitchell and Husak, 2021). But the actual design of such automatic extensions has not been the subject of much previous analysis. In this paper, we develop a simulation model to analyze the tradeoffs inherent in different extension policies.

We reach three conclusions. First, policies designed to trigger immediately at the onset or even before a recession starts result in benefit extensions that occur in less sick labor markets than the historical average for benefit extensions. Second, the ad hoc extensions in past recessions in total cover a similar number of additional weeks as common proposals for automatic triggers, but have better targeting in the sense of concentrating coverage more in weaker labor markets when unemployment is especially high and job vacancies are especially low. This conclusion comes with the important disclaimer that past behavior is no guarantee of future legislative performance and that there may be other benefits to automating policy. Third, compared to ex post policy, the cost of more systematic policy is close to zero.

\section{The UI Policy Simulator Model}

The UI Policy Simulator combines a simulated history of unemployment duration lengths with benefit levels to arrive at a simulated panel of individuals with complete labor force histories over the period 1996-2019, grouped by state. The simulated history of unemployment duration lengths follows the procedure in Chodorow-Reich and Coglianese (2019, 2021). Each simulated individual may be employed, on temporary layoff, other UI eligible, unemployed ineligible, or out of the labor force in a given week. Individuals transition across these statuses with probabilities that obey a factor structure of aggregate labor market transition probabilities and individual history dependence and that aggregate to the gross flows transition rates across employment, unemployment, and out of the labor force published by the BLS. 


\section{Trigger Design}

We use the Simulator to consider three design issues in the construction of automatic triggers for enhanced benefits. The first is the issue of when benefits should "trigger on": when the level of the running variable crosses a threshold, or also when the change is sufficiently large? The rationale for considering the change is that workers unlucky enough to be long-term unemployed at the start of a recession would otherwise be without benefits until unemployment rose high enough and triggering earlier may also have aggregate demand benefits by increasing consumption of the unemployed. For example, the national unemployment rate did not cross the EB threshold of $6.5 \%$ until October 2008, 10 months into the Great Recession.

We consider a "Sahm trigger", following Sahm (2019). That paper suggests that national recessions are well predicted by a rise in the unemployment rate of 0.5 percentage points above the minimum of its three month average the previous 12 months, suggesting that benefits could trigger on in that scenario. Converting the Sahm trigger to the UI context raises the question of whether the trigger should "fire" based on state or national unemployment rates; while state triggers allow more responsiveness to the timing of recession onset across states, they introduce noise because of the difficulty of estimating state-level unemployment rates in real-time (Chodorow-Reich, Coglianese and Karabarbounis, 2019).

Figure 1 illustrates the trade-off by comparing a national Sahm rule with a trigger of 0.5p.p. to state Sahm rules with thresholds of 0.5p.p. or 1p.p. The $\mathrm{X}$ axis in each graph is the difference between state unemployment six months after a trigger fires and the state's unemployment rate at the time that it fires; positive values mean that the unemployment rate went up, while negative values mean that it actually went down. In about half the cases where the national Sahm fires, state unemployment rates subsequently rise by at least 1p.p. and in all cases they do not fall. In contrast, with a state Sahm trigger of 1p.p. or especially 0.5p.p., the unemployment rate frequently remains stable or even falls after the trigger fires. These "false positives" in part reflect the difference between the real-time data used to determine a trigger firing and the revised data used to measure the subsequent unemployment rate change. Conversely, the national trigger misses few cases when unemployment subsequently rises steeply and the state data catch. We therefore conclude that a national trigger is preferred and model a national Sahm rule providing 0, 26, or 52 additional weeks of benefits for six months.

The second issue is how to set triggers that depend on the level of the state unemployment rate and hence also determine when a state triggers off. Choices here include the variation in duration extensions due to higher unemployment rates and the number of "tiers" of benefit extensions based on various unemployment rate cutoffs. We model three options: a one tier extension of 26 weeks when the unemployment rate exceeds $6.5 \%$; a three tier extension that adds 26 weeks when the unemployment rate reaches $6.5 \%, 39$ weeks when the unemployment rate reaches $7.5 \%$, and 52 weeks when the unemployment rate reaches $8.5 \%$; and a four tier extension which adds to the three tier version an extra tier that adds 13 weeks when the unemployment rate reaches $5.5 \%{ }^{1}$.

The final policy option is the extent of "soft" versus "hard" landings for those who are unemployed when a trigger turns off. Concretely, consider a system with a trigger that extends unemployment benefits by 26 weeks if the unemployment rate is above $6.5 \%$. Suppose an individual has been collecting extended benefits for 6 weeks when the unemployment rate drops below $6.5 \%$. Should the individual

\footnotetext{
${ }^{1}$ We focus on unemployment rate triggers because they have been the traditional mechanism. An interesting avenue for future research would be to consider jointly the unemployment rate and the new state-level vacancy data released by the BLS JOLTS program.
} 
immediately lose the remaining weeks of unemployment (a "hard landing") or should they be allowed to keep some or all of the remaining weeks of entitlement (a "soft landing")?

\section{Results}

We use the Simulator to assess 18 scenarios, defined as Sahm rule specification X number of tiers X hard/soft landing. We simulate the experience over the period 2001-2015, covering both the onset and aftermath of the 2001 and 2007-09 recessions. Table 1 shows our results. The first three columns describe the trigger on, tiers, and hard/soft landing policies. The next columns show the total weeks of extended UI that would have been claimed under the policy, the total weeks of long-term unemployment uncovered, and the coverage ratio (ignoring behavioral responses). The final two columns show how well the extended benefits are targeted by computing the weighted average total unemployment rate and vacancy-unemployment ratio in the state-months that extended benefits are available, weighted by the number of recipients. Policies that deliver the most benefits during periods of high unemployment

or a low vacancy/ unemployment rate are better targeted. The last row of the table computes these same statistics for the actual ex-post extension policy implemented by Congress.

\subsection{Evaluating Early Onset Policies}

Our first conclusion concerns the Sahm rule. For every specification of number of tiers and landing weeks, no Sahm trigger results in the average week of extended benefits being received when the labor market is more slack (the average $v / u$ rate is lower and $u$ is higher). This result reflects the fact that the Sahm rule can trigger on when unemployment is very low but starting to rise.

\subsection{Comparison to Historical Policy}

Our second conclusion comes from comparing the alternative policies to the actual ex-post extension policy implemented by Congress. To visualize this comparison, Figure 2 shows the relationship between the fraction of regular program exhaustees covered (equivalently, total cost) and the weighted average vacancy/unemployment rate ratio when additional benefits are claimed. By construction, additional tiers cover more long-term unemployed covered, as shown by the rightward shift of the grey to the blue and the red frontiers. The large black circle shows the actual historical experience. Historical coverage is comparable to the four tier policy without a Sahm trigger or the three tier policy with a 26 week Sahm trigger. Moreover, the fact that it lies below the alternative policy indicators means that Congress has extended benefits in periods when the labor market was on average weaker than what would have occurred under the automatic policies considered, holding fixed total cost.

This result may appear surprising in light of conventional wisdom that discretionary fiscal policy contains long and variable political and implementation lags (Blanchard and Perotti, 2002). Nonetheless, the ad hoc nature of the historical extensions creates several important risks. First, UI extensions become a political object; emergency benefits lapsed seven different times between 2002-2012 and again at the start of 2021, with potentially dire consequences for the temporary exhaustees (Ganong and Noel, 2019). Second, historical policy has involved extreme course corrections, such as the reduction from 67 to 0 potential additional weeks in January 2014. Third, systematic policy facilitates workers' ability to optimally plan consumption and search and may generate aggregate demand benefits by reducing the 
precautionary saving motive of employed workers (Kekre, 2021). Fourth, past behavior is no guarantee of future legislative performance.

\subsection{Cost of Policy Reform}

Perhaps the most important political barrier to reforming the system of benefit duration extensions is that such changes generate up-front costs when scored by the Congressional Budget Office (CBO) but have no immediate benefit if the economy is not already in recession ${ }^{2}$. The comparison of historical experience to the alternative polices considered challenges that logic. The coverage and cost of historical ad hoc policy is similar to the three and four tier policy alternatives. Therefore, viewed against a current policy baseline that projects forward past ad hoc extensions, automating additional benefit extensions has little to no additional cost.

\section{Conclusions}

There is a strong presumption that the generosity of the system should depend on the state of the economy. This has been recognized in each recession over the past 40 years on an ex-post basis by Congress. We compare a variety of options for designing automated triggers to the ex-post actions. Our model can also be combined with a simulation of individual benefit amounts (Ganong, Noel and Vavra, 2020) and used for other questions of policy interest, including the cost and distributional consequences of changing benefit amounts or eligibility.

\footnotetext{
${ }^{2}$ The CBO evaluates policies such as UI reform using a probabilistic score that accounts for the uncertainty around its baseline economic projections and in particular the possibility that the economy might enter a recession in the future. It compares the expected cost of the alternative policy to current law.
} 


\section{References}

Blanchard, O., and R. Perotti. 2002. "An Empirical Characterization of the Dynamic Effects of Changes in Government Spending and Taxes on Output." The Quarterly Journal of Economics, 117(4): 1329-1368.

Chodorow-Reich, Gabriel, and John Coglianese. 2019. "Unemployment Insurance and Macroeconomic Stabilization." In Recession Ready: Fiscal Policies to Stabilize the American Economy., ed. Heather Boushey, Ryan Nunn and Jay Shambaugh, 153-179. Washington, D.C.:Brookings Institution. Backup Publisher: Brookings Institution.

Chodorow-Reich, Gabriel, and John Coglianese. 2021. "Projecting unemployment durations: A factor-flows simulation approach with application to the COVID-19 recession." Journal of Public Economics, 197: 104398.

Chodorow-Reich, Gabriel, John Coglianese, and Loukas Karabarbounis. 2019. "The Macro Effects of Unemployment Benefit Extensions: a Measurement Error Approach." The Quarterly Journal of Economics, 134(1): 227-279.

Ganong, Peter, and Pascal Noel. 2019. "Consumer Spending during Unemployment: Positive and Normative Implications." American Economic Review, 109(7): 2383-2424.

Ganong, Peter, Pascal Noel, and Joseph Vavra. 2020. "US unemployment insurance replacement rates during the pandemic." Journal of Public Economics, 191(C): 104273.

Kekre, Rohan. 2021. "Unemployment Insurance in Macroeconomic Stabilization." Unpublished manuscript.

McKay, Alisdair, and Ricardo Reis. 2021. "Optimal Automatic Stabilizers." The Review of Economic Studies, 88(5): 2375-2406.

Mitchell, David, and Corey Husak. 2021. "How to replace COVID relief deadlines with automatic 'triggers' that meet the needs of the U.S. economy." The Washington Center for Equitable Growth.

Sahm, Claudia. 2019. "Direct Stimulus Payments to Individuals." In Recession Ready: Fiscal Policies to Stabilize the American Economy. ed. Heather Boushey, Ryan Nunn, and Jay Shambaugh. 
Figure 1: National versus State early Trigger
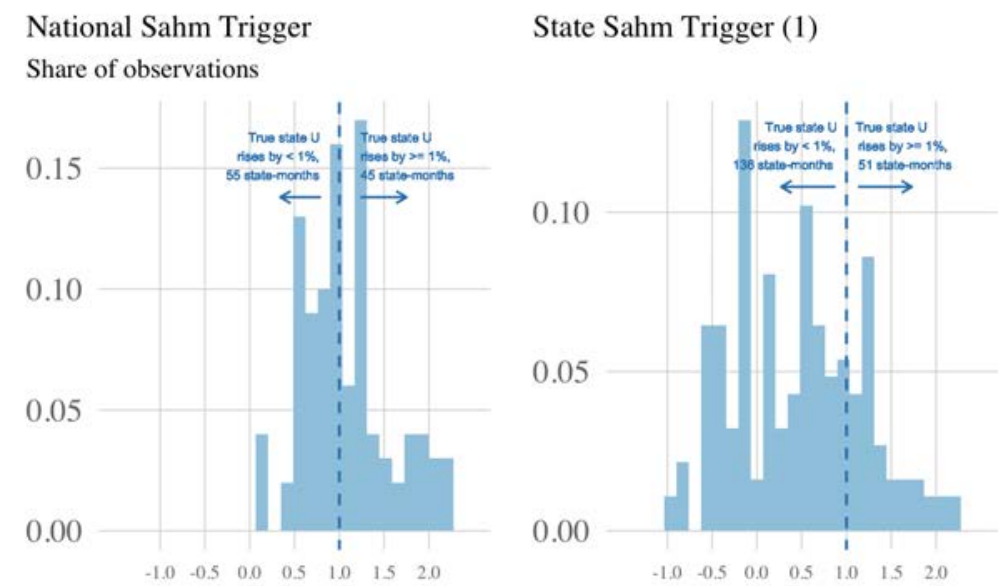

State Sahm Trigger (0.5)

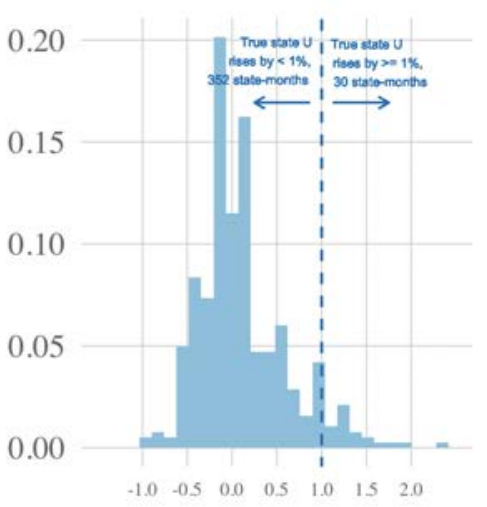

Excess unemployment in 6 months (p.p)

Notes: This figure shows the change in the revised unemployment rate in the six months after a Sahm trigger is active. The left panel shows when a Sahm trigger of 0.5 percentage points (p.p.) using the national unemployment rate is active, the middle panel shows when a Sahm trigger of 1.0 p.p. using the real-time state unemployment rate is active, and the right panel shows when a Sahm trigger of 0.5 p.p. using the real-time state unemployment rate is active. 
Table 1: Comparison of Alternative Policies and Historical Experience

\begin{tabular}{llllllll}
\hline \hline $\begin{array}{l}\text { Sahm } \\
\text { weeks }\end{array}$ & Tiers & $\begin{array}{l}\text { Landing } \\
\text { weeks }\end{array}$ & $\begin{array}{l}\text { Total weeks } \\
\text { claimed } \\
\text { (millions) }\end{array}$ & $\begin{array}{l}\text { Total weeks } \\
\text { uncovered } \\
\text { (millions) }\end{array}$ & $\begin{array}{l}\text { Proportion of } \\
\text { weeks } \\
\text { uncovered }\end{array}$ & $\begin{array}{l}\text { Weighted } \\
\text { v over u }\end{array}$ & $\begin{array}{l}\text { Weighted } \\
\text { tur }\end{array}$ \\
\hline 0 & 1 & 0 & 437 & 876 & 0.67 & 1.23 & 8.9 \\
0 & 1 & 13 & 449 & 863 & 0.66 & 1.28 & 8.82 \\
0 & 3 & All 0 & 583 & 730 & 0.56 & 1.16 & 9.2 \\
0 & 3 & All 13 & 602 & 711 & 0.54 & 1.2 & 9.11 \\
0 & 4 & All 0 & 678 & 635 & 0.48 & 1.37 & 8.7 \\
0 & 4 & All 13 & 696 & 617 & 0.47 & 1.41 & 8.63 \\
\hline 26 & 1 & 0 & 502 & 810 & 0.62 & 1.44 & 8.29 \\
26 & 1 & 13 & 514 & 799 & 0.61 & 1.47 & 8.24 \\
26 & 3 & All 0 & 654 & 659 & 0.5 & 1.32 & 8.67 \\
26 & 3 & All 13 & 672 & 641 & 0.49 & 1.35 & 8.62 \\
26 & 4 & All 0 & 721 & 592 & 0.45 & 1.48 & 8.42 \\
26 & 4 & All 13 & 737 & 575 & 0.44 & 1.46 & 8.37 \\
\hline 52 & 1 & 0 & 593 & 719 & 0.55 & 1.49 & 7.99 \\
52 & 1 & 13 & 604 & 708 & 0.54 & 1.38 & 8.39 \\
52 & 3 & All 0 & 719 & 594 & 0.45 & 1.42 & 8.34 \\
52 & 3 & All 13 & 736 & 576 & 0.44 & 1.52 & 8.25 \\
52 & 4 & All 0 & 760 & 553 & 0.42 & 1.27 & 8.21 \\
52 & 4 & All 13 & 777 & 536 & 0.41 & 0.49 & 8.21 \\
\hline
\end{tabular}

Notes: This table compares the coverage and targeting of several policy options for automatic triggers to historical experience of actual extensions for 2001-2015. The policy options are the number of tiers of extended benefits, the availability of additional weeks of benefits from a national Sahm trigger, and whether additional benefits are available after a tier turns off. TUR is the total unemployment rate. 
Figure 2: Coverage versus Targeting

\section{Weighted vacancy/unemployment ratio}

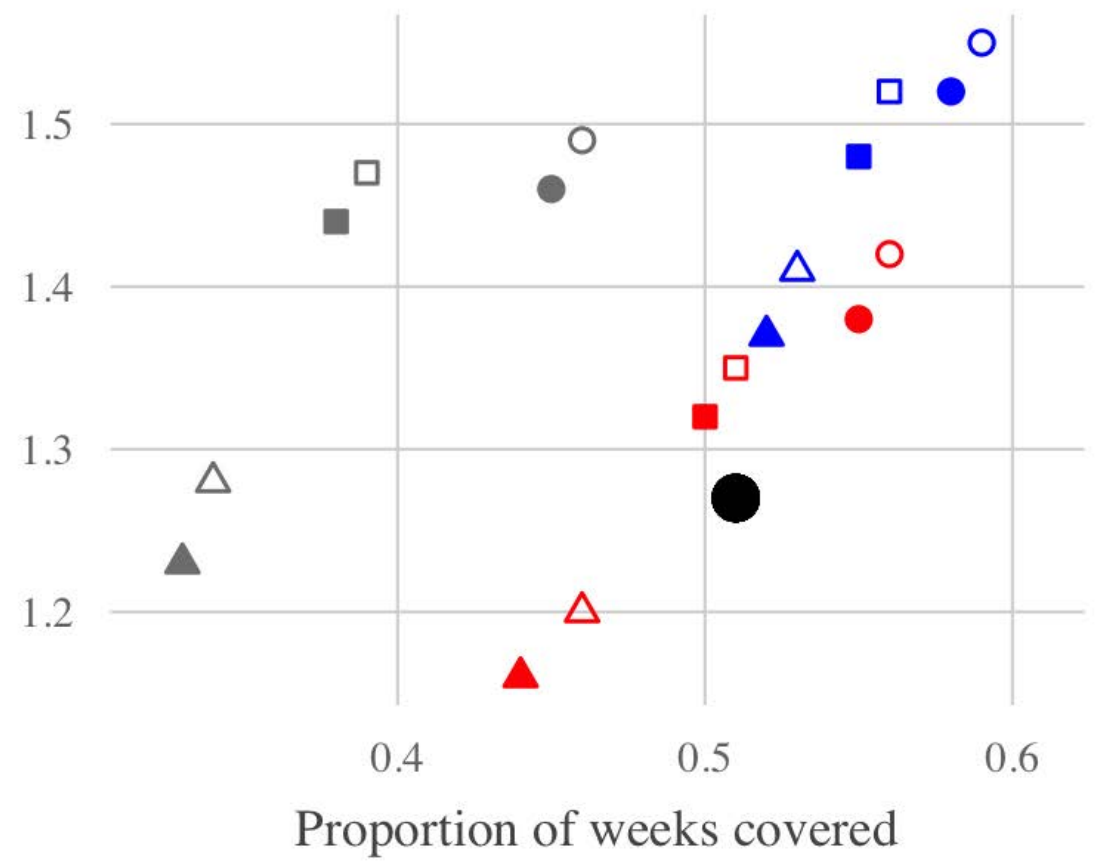

1 Tier 3 Tier 4 Tier

\section{$\Delta 0 \mathrm{Sahm}$ Weeks $\boldsymbol{2} 26 \mathrm{Sahm}$ Weeks $\mathrm{O} 52 \mathrm{Sahm}$ Weeks \\ O Hard Landing O Soft Landing Historical}

Notes: This figure shows the trade-off between covering more of the long-term unemployed (shown on the x-axis) and targeting extended benefits to periods of worse labor market health (shown on the y-axis). We compare several policy options for automatic triggers to historical experience of actual extensions for 2001-2015. The policy options are the number of tiers of extended benefits (in gray, red, and blue), the availability of additional weeks of benefits from a national Sahm trigger (different shapes), and whether additional benefits are available after a tier turns off. 